\title{
Lenglet Dufresnoy entre ombre et lumières, éds. Claudine Poulouin et Didier Masseau
}

Regina Bochenek-Franczakowa

\section{(2) OpenEdition}

1 Journals

Édition électronique

URL : http://journals.openedition.org/studifrancesi/4369

DOI : 10.4000/studifrancesi.4369

ISSN : 2427-5856

Éditeur

Rosenberg \& Sellier

Édition imprimée

Date de publication : 1 septembre 2016

Pagination : 329

ISSN : 0039-2944

\section{Référence électronique}

Regina Bochenek-Franczakowa, «Lenglet Dufresnoy entre ombre et lumières, éds. Claudine Poulouin et Didier Masseau », Studi Francesi [En ligne], 179 (LX | II) | 2016, mis en ligne le 01 septembre 2016, consulté le 18 septembre 2020. URL : http://journals.openedition.org/studifrancesi/4369 ; DOI : https://doi.org/10.4000/studifrancesi.4369

Ce document a été généré automatiquement le 18 septembre 2020

\section{(c) (†) $\odot$}

Studi Francesi è distribuita con Licenza Creative Commons Attribuzione - Non commerciale - Non opere derivate 4.0 Internazionale. 


\title{
Lenglet Dufresnoy entre ombre et lumières, éds. Claudine Poulouin et Didier Masseau
}

\author{
Regina Bochenek-Franczakowa
}

\section{RÉFÉRENCE}

Lenglet Dufresnoy entre ombre et lumières, Claudine POULouIN et Didier MASSEAU éds., Paris, Honoré Champion, 2013, 328 pp.

1 Lenglet Dufresnoy, «ni philosophe, ni véritablement historien, pas davantage romancier, [...] érudit [...] mais "excentrique"»; en somme, un «irrégulier d'esprit vraiment libre» déconcertant ses contemporains et resté, jusqu'à nos jours, un «inclassable» (Préface, p. 7). Voilà le personnage objet du volume, que nous présentons avec un retard qui n'est pas imputable à notre volonté. Les études qui y sont contenues sont donc réparties en quatre groupes, afin de mieux saisir toute l'activité débordante et un peu composite de ce personnage saillant des Lumières. La première partie («Lenglet Dufresnoy-homme du livre») s'occupe d'un des champs de l'activité de Lenglet liés au marché du livre: bibliographies, édition des livres rares et des œuvres du passé, diffusion. Lenglet y apparaît comme «un militant de l'imprimé» (Géraldine SHERIDAN, Lenglet Dufresnoy entre élite et grand public, pp. 33-55; Jean-Marie GOULEMOT, Imaginaire et réalité du livre chez Lenglet Dufresnoy, pp. 57-69; François BESSIRE, Lenglet Dufresnoy éditeur. Une pensée du livre et de la lecture, pp. 71-101). Dans la deuxième partie («Une érudition recentrée sur le passé national»), nous trouvons des études qui présentent Lenglet en tant qu'éditeur érudit et bibliophile intéressé par les œuvres françaises du Moyen Âge et de la Renaissance: Gabrielle PARUSSA démontre en quoi consiste l'originalité de la démarche de Lenglet amateur de la littérature médiévale (Littérature médiévale d'après Lenglet Dufresnoy, pp.105-127), Marie-Claude de CRÉCY examine l'entreprise éditoriale de Lenglet à la lumière de ce que deviendra plus tard la 
philologie moderne (Lenglet Dufresnoy éditeur de «nos anciens Poëtes», pp. 129-162). L'amour de la littérature ancienne menait Lenglet parfois à des plagiats: Claudine poulouin en examine un cas flagrant ("L'Histoire de Jeanne d'Arc" de Lenglet Dufresnoy: plagiat, hétérodoxie et révision de l'histoire nationale, pp.163-190). La troisième partie («Lenglet Dufresnoy et la mise en circulation des savoirs») est centrée sur les ouvrages de Lenglet à prétention scientifique, avant tout ses Méthode pour étudier l'histoire et Méthode pour étudier la géographie qui eurent un succès notoire, à portée internationale (Béatrice GUION, $\mathrm{La}$ "Méthode pour étudier l'histoire" de Lenglet Dufresnoy: un "ars historica" composite, pp. 193-210; Gérard LAUDIN, Europe savante et érudition nationale. Les Enjeux de la réception de la "Méthode pour étudier l'histoire" de Lenglet Dufresnoy dans l'Allemagne des Lumières, pp. 211-225; Jean-François THÉMINES, Lenglet Dufresnoy géographe?, pp. 227-225). Dans la quatrième partie de l'ouvrage («Importance de la fiction dans l'accroissement des savoirs») les auteurs mettent en valeur l'intérêt de Lenglet pour la fiction romanesque. À l'époque où celle-ci était l'objet de litiges et d'attaques, Lenglet s'est prononcé pour la supériorité de la fiction sur le récit historique, insistant aussi sur le plaisir de la lecture: il semble avoir deviné les orientations du roman au XVIII ${ }^{\mathrm{e}}$ siècle (Didier MASSEAU, Comment lire les romans?, pp. 253-266). Jan HERMAN fait une présentation détaillée d'un manuscrit trouvé récemment, signé «Gordon de Percel» qu'on peut attribuer à Lenglet et qui contient quelques parties des écrits de celui-ci sur le roman (Un manuscrit trouvé de Gordon de Percel, pp. 267-280). Marie-Gabrielle LALLEMAND présente la nouvelle de Lenglet qui est une compilation d'une œuvre historique inédite de Pierre Matthieu (La Fabrique de la nouvelle histoire galante. L'exemple de "La Catanoise" (1731), pp.281-299). À la fin de l'ouvrage, le lecteur trouvera la Bibliographie chronologique des cuvres de Nicolas Lenglet Dufresnoy (pp. 301-314). 